\title{
Producción de BIOETANOL a PARTIR de diferentes MEZCLAS DE LOS RESIDUOS ORGÁNICOS GENERADOS EN UNA EMPRESA ALIMENTOS
}

\author{
BIOETHANOL PRODUCTION FROM DIFFERENT MIXES OF ORGANIC WASTES \\ IN A FOOD COMPANY
}

Martha Lucía Malagón Micán*

Adriana Inés Paéz ${ }^{* *}$

Andrea Lache Muñoz***

Judith Santos Aguilar*****

Diego A. Zabala García*****

Recibido: 11 de enero de 2017

Aceptado: 25 de abril de 2017

\section{Resumen}

Este estudio evalúa la producción de bioetanol a partir de residuos lignocelulósicos generados en una industria de producción de pulpa de fruta, describe la selección y caracterización de los residuos y analiza el rendimiento de bioetanol. Inicialmente, la investigación determinó la disponibilidad que en 2015 tuvieron los residuos (cáscaras y semillas) de las frutas seleccionadas, lo que permitió establecer que los residuos de mora, limón, maracuyá, lulo y mango son los más convenientes. La similitud en el porcentaje de celulosa de los residuos permitió realizar las siguientes mezclas: limón-lulo, maracuyá-lulo, maracuyá-limón y mora-mango. Posteriormente, a los residuos se les realizó un pretratamiento con hidróxido de sodio y una hidrólisis empleando la enzima Multifect B; se determinó la cantidad de azúcares reductores mediante el método DNS; se empleó una cepa etanólica para el proceso de fermentación; se realizó una destilación simple, y se determinó el bioetanol por el método de dicromato de potasio. Se estableció que la mezcla de residuos de lulolimón fue la de mayor concentración de azúcares reductores, con 2.08 g glucosa/L mezcla y un rendimiento de $9.22 \mathrm{~g}$ bioetanol $/ \mathrm{kg}$ de residuos. E1 rendimiento producto/sustrato fue de $0.87 \mathrm{~g}$

\footnotetext{
* Ingeniera química, magíster en Ingeniería Química, magíster en Docencia. Docente investigador, grupo de investigación BIOTECFUA, Fundación Universidad de América. martha.malagon@profesores.uamerica.edu.co

${ }^{\star \star}$ Microbióloga industrial, magíster en Ciencias. Docente investigador, grupo de investigación Energías Alternativas, Fundación Universidad de América. adriana.paez@profesores.uamerica.edu.co

${ }^{* * *}$ Ingeniera química, magíster en Energías Renovables, Pilas de Combustible e Hidrógeno. Docente investigador, grupo de investigación Energías Alternativas, Fundación Universidad de América. andrea.lache@investigadores.uamerica.edu.co

**** Estudiante coinvestigador, grupo de investigación BIOTECFUA, Fundación Universidad de América. judsan92@hotmail.com

***** Estudiante coinvestigador, grupo de investigación BIOTECFUA, Fundación Universidad de América. diegoz893@hotmail.com
} 
bioetanol/g glucosa en promedio, lo que mostró que la producción de bioetanol de segunda generación, a partir de residuos lignocelulósicos a nivel de laboratorio, es satisfactoria (comparada con otros estudios) y que podría escalarse para valorizar los residuos y disminuir el impacto ambiental que estos generan

Palabras clave: bioetanol, residuos lignocelulósicos, celulosa, hidrólisis enzimática, fermentación.

\section{Abstract}

This study evaluates the production of bioethanol from lignocellulosic residues generated in a fruit pulp production industry. It also describes the selection and characterization of the residues and analyzes bioethanol yield. Initially, the availability of residues such as husks and seeds of selected fruits was analyzed throughout 2015, which allowed us to establish that residues of blackberry, lemon, passion fruit, lulo and mango are the most convenient. Considering the similarity in the percentage of cellulose of the residues the following combinations of the same were determined: lemon-lulo, passion fruit, lemon passion fruit and mora-mango. Afterwards they were pre-treated with sodium hydroxide, then a hydrolysis using the enzyme Multifect B, the amount of reducing sugars was determined by the DNS method and an ethanolic strain was used for the fermentation process. Finally, a simple distillation was carried out and the bioethanol was determined by the potassium dichromate method. It was established that the mixture of lulo-lemon residues was the highest concentration of reducing sugars, with $2.08 \mathrm{~g}$ glucose/L mixture and a yield of $9.22 \mathrm{~g}$ bioethanol $/ \mathrm{kg}$ of residues. The yield of the product / substrate was $0.87 \mathrm{~g}$ bioethanol $/ \mathrm{g}$ glucose on average, showing that the production of second generation bioethanol, from lignocellulosic residues at the laboratory level, compared to other studies, is satisfactory and could be scaled with the purpose of valorizing the residues and diminishing the environmental impact that they generate.

Keywords: bio-ethanol, lignocellulosic residues, cellulose, enzymatic hydrolysis, fermentation.

\section{INTRODUCCIÓN}

El impacto ambiental generado por el uso de combustibles fósiles ha impulsado la investigación, desarrollo y aplicación de fuentes alternativas y renovables de energía que permitan reducir las emisiones atmosféricas contaminantes y suplir la creciente demanda de energía (Amarís, Manrique y Jaramillo, 2015). La biomasa es una de las fuentes alternativas de la que se pueden obtener diferentes tipos de biocombustibles (líquidos y gaseosos), como el bioetanol, que ha llamado la atención por su uso en el sector transporte. En Colombia se produce bioetanol a escala industrial a partir de los cultivos de caña de azúcar o maíz; sin embargo, el empleo de estos cultivos para la producción de combustible ha generado una discusión en torno a la seguridad alimentaria, al precio de los alimentos y sobre el uso de estos para fines energéticos (Serna, Barrera y Montiel, 2011).

Algunas investigaciones están desarrollando procesos para la obtención de bioetanol y otros biocombustibles a partir de los residuos sólidos generados por la industria de alimentos. Estos estudios revalorizan los residuos, lo que contribuye a disminuir el impacto ambiental que estos pueden generar y permite diversificar las alternativas para combustibles que demanda el sector transporte. Colombia se comprometió a reducir la emisión de gases efecto invernadero en un 30 \% (Ministerio de Ambiente y Desarrollo Sostenible, 2015); para lograr esta reducción una de las metas es promover el uso de vehículos con menor intensidad de carbono. Es por esto que se hace necesario el desarrollo a escala comercial de biocombustibles de segunda generación, es decir, obtenidos a 
partir de residuos lignocelulósicos, que es el objetivo general de este proyecto (actualmente, en etapa de laboratorio).

Con el fin de aprovechar los residuos generados por una empresa de alimentos que produce jugos y pulpas de dieciséis frutas diferentes, se seleccionaron los desechos orgánicos (cáscaras y semillas) de las seis frutas que generan mayor volumen de residuos. Para la disposición final de los residuos, la empresa ha contemplado alternativas como el compostaje o el uso de estos como complemento para la fabricación de alimento para ganado. Esta investigación estudia la posibilidad de producir bioetanol a partir de los residuos generados por la empresa, mediante hidrólisis enzimática y fermentación, y propone como objetivos específicos la selección y caracterización de los residuos y la formulación de mezclas de acuerdo con la similitud en el contenido de glucosa, así como la evaluación del rendimiento de la producción de bioetanol.

Este artículo describe el proceso que se llevó a cabo para la obtención final de etanol a partir de los residuos disponibles en la empresa y analiza los resultados obtenidos en cada una de las etapas, enfatizando en el rendimiento final de volumen de etanol producido con relación a la cantidad de residuos empleados en la experimentación.

\section{MATERIALES Y MÉTODOS}

El procedimiento investigativo y de laboratorio contempló inicialmente la caracterización de los residuos y la formulación de las mezclas; luego se realizó el pretratamiento de los residuos, para llevarlos posteriormente a procesos de hidrólisis enzimática, fermentación y destilación con el fin de obtener bioetanol.

\section{Selección de los residuos}

El criterio para determinar los residuos de las frutas se basó en parámetros fisicoquímicos (sólidos totales y $\mathrm{pH}$ ) y operacionales (cantidad y frecuencia de residuos). Los parámetros operacionales fueron los primeros en ser evaluados, puesto que es importante determinar qué residuos están disponibles de manera estable a lo largo del año y cuáles son potenciales para producir cantidades significativas de bioetanol.

Los resultados para estos dos primeros parámetros fueron dados como el promedio de los datos de compra mes a mes de cada fruta en los últimos tres años (2013-2015) y los porcentajes de desperdicio de cada una, los cuales son muy cercanos a los encontrados en la literatura (Márquez,2009). Por medio de una matriz de ponderación, se seleccionaron los residuos con mayor calificación con respecto a los parámetros operacionales y, una vez seleccionados, se evaluaron los otros parámetros.

La determinación de los sólidos solubles totales permitió reconocer la cantidad de compuestos (azúcares y otros compuestos) que son solubles en agua y están presente en los residuos de las frutas que se utilizaron para la obtención de etanol. Con una primera selección de sustratos fermentables se identificaron los residuos de limón, lulo, mango, maracuyá, mora y piña como materias primas importantes y que pueden ser considerados para el desarrollo del proyecto en cuanto a cantidad y frecuencia.

\section{Caracterización de los residuos orgánicos}

Los residuos se caracterizaron por medio de acidez titulable (conforme a la norma AOAC 930.35), cuyo resultado se expresa en gramos de ácido cítrico, ya que es el predominante en el limón (Domínguez et ál., 2003), la piña (Martínez, del Ángel, Martínez, Román y Uriza, 2006), el mango en estado maduro (Siller, Muy, Báez, Araiza y Araiza, 2009) y el maracuyá (Rodríguez, López y García, 2010) por cada $100 \mathrm{~g}$ de muestra. El ácido málico predomina en la mora (Montoya, 
Londoño y Márquez, 2005) y el lulo. El porcentaje de celulosa se estimó con el método descrito por Van Soest and Wine (Segura, Echeverry, Patiño y Mejía, 2007); la densidad, por el principio de Arquímedes, y el porcentaje de humedad, por la norma AOAC 16.032 de 1984.

\section{Determinación de las diferentes combinaciones de los residuos de fruta}

Sobre la base de la caracterización de los residuos y con la finalidad de aprovechar el mayor volumen de los mismos en un único proceso de fermentación, se establecieron mezclas de estos a partir de los mismos obtenidos en la determinación de celulosa. De acuerdo con lo anterior, las mezclas se definieron entre los desechos que presentaban concentraciones de celulosa cercanas, y se realizó un proceso de hidrólisis y fermentación individual. Las combinaciones estuvieron formadas por dos residuos de fruta.

\section{Pretratamiento de los residuos}

Antes de iniciar el proceso de hidrólisis enzimática en los residuos, fue necesario realizar pretratamientos físicos y químicos para romper la lignina (la lignina es un polímero que actúa como soporte estructural de la celulosa e impide su hidrólisis).

Para los pretratamientos, se pesaron $2 \mathrm{~kg}$ de cada residuo en el caso de la hidrólisis individual y en las mezclas se pesó $1 \mathrm{~kg}$ de cada uno de los residuos a combinar.

\section{Pretratamientos físicos}

Molienda. Se pesaron $2 \mathrm{~kg}$ de cada materia prima y se sometieron a molienda mediante un molino de disco, para disminuir el tamaño de la materia prima y así tener un área mayor de contacto entre el sustrato y los reactivos químicos.

Lavado. Los residuos se sumergieron en agua a punto de ebullición durante $2 \mathrm{~h}$.

\section{Pretratamiento químico}

Pretratamiento con $\mathrm{NaOH}$. Los residuos fueron sumergidos en una solución de $\mathrm{NaOH} 0.5 \mathrm{~N}$ durante $2 \mathrm{~h}$ y con agitación constante. Posteriormente, se filtró y se realizaron 4 lavados con agua potable, para garantizar que no quedaran residuos del hidróxido que pudieran afectar la hidrólisis.

Después de los pretratamientos, se determinó el $\mathrm{pH}$ de las muestras y se agregó la cantidad de buffer HI 7004 Buffer Solution $\mathrm{pH} 4.01$ necesaria para alcanzar un $\mathrm{pH}$ de 4.0-6.0 y para que la enzima pueda actuar.

\section{Hidrólisis enzimática}

Se realizó con el complejo multifect B de Genencor. Se utilizó una cantidad igual para todos los residuos de $3.86 \mathrm{~mL}$. A cada muestra se le agregaron $2 \mathrm{~L}$ de agua y se verificó que quedara totalmente sumergida. La temperatura se mantuvo en un intervalo de $48{ }^{\circ} \mathrm{C}$ a $52{ }^{\circ} \mathrm{C}$ y pH $5-6$ para garantizar la actividad de la enzima. El proceso se realizó en un lapso de $3 \mathrm{~h}$ (Forero, López y Malagón, 2008). Finalmente, se filtraron las muestras y se obtuvo un volumen final hidrolizado.

Con las muestras hidrolizadas, se determinó la cantidad de azúcares reductores presentes; factor que es un parámetro determinante para la obtención de bioetanol.

\section{Determinación de azúcares reductores por el método del DNS}

La curva de calibración se realizó con la preparación de 10 muestras de glucosa, concentraciones de $0-1 \mathrm{~g} / \mathrm{L}$ de glucosa y la medición de absorbancias. Se tomaron $0.25 \mathrm{~mL}$ de cada una de las 
muestras hidrolizada y filtrada y se agregó $0.25 \mathrm{~mL}$ de reactivo DNS. Luego se calentó hasta la reducción en un baño maría, se sumergió en agua fría, se agregaron $2.5 \mathrm{~mL}$ de agua destilada y se llevó al espectrofotómetro, donde se leyó la absorbancia a $540 \mathrm{~nm}$ de longitud de onda (el blanco se preparó con $0.25 \mathrm{~mL}$ de agua destilada y $0.25 \mathrm{~mL}$ de reactivo DNS). El método tuvo dos repeticiones para cada residuo y mezcla (Miller, 1959).

\section{Fermentación}

En la preparación del inóculo se utilizó el medio de cultivo Sabouraud Broth de Scharlab S. L. $30 \mathrm{~g} / \mathrm{L}$ estéril en una autoclave a $121^{\circ} \mathrm{C}$ y 15 psia durante 1 h. Se empleó la cámara Neubauer para ajustar la concentración del inóculo, hasta que se obtuvo una concentración inicial de $1 \times 10^{7}$ y 1 x $10^{8}$ células $/ \mathrm{mL}$.

E1 producto obtenido de la hidrólisis se esterilizó, luego se adicionó el inóculo y se llevó a incubación a $23^{\circ} \mathrm{C}$. Se tomaron muestras cada $12 \mathrm{~h}$ para determinar la curva de crecimiento de la levadura, utilizando el método directo de conteo con cámara de Neubauer.

\section{Destilación}

La destilación se realizó con $250 \mathrm{~mL}$, durante 2 h y en un intervalo de temperatura de $70-80^{\circ} \mathrm{C}$. Al final, el volumen destilado se acumuló en el balón aforado de $100 \mathrm{~mL}$ y a este volumen se le determinó la concentración de bioetanol mediante el método del dicromato de potasio (Vanegas y Zapata, 2009).

\section{Rendimiento de bioetanol}

Como definición general, el rendimiento de bioetanol se entiende como la cantidad de etanol que se produce por cantidad de materia prima:

$$
R_{B}=\frac{V_{H} * C_{R}}{2000 g}
$$

Donde $R_{B}$ es la cantidad de gramos de bioetanol que se producen por cada gramo de residuo de fruta; $V_{H}$ es el volumen final hidrolizado de cada muestra, y $C_{R}$ es la concentración de etanol que se puede obtener para todo el volumen hidrolizado.

\section{Rendimiento de la fermentación}

En el proceso de fermentación se consideran dos rendimientos importantes: el rendimiento $Y x / s$ expresa la cantidad de biomasa producida a partir del sustrato consumido (que es afectado por variables como la composición del medio, la naturaleza de las fuentes de carbono y nitrógeno, el $\mathrm{pH}$, la temperatura y la concentración de oxígeno); y el rendimiento del producto a partir del sustrato $Y_{P /}$, que es el más relevante desde el punto de vista económico (Buitrago y Tenjo, 2007).

$$
Y_{P / S}=\frac{\text { Producto formado }(\text { etanol })}{\text { Consumo de sustrato }}
$$




\section{Resultados y discusión}

\section{Caracterización de residuos orgánicos sólidos}

En la tabla 1 se presentan los resultados obtenidos en la caracterización de los residuos de fruta.

Tabla 1. Caracterización de los residuos de fruta

\begin{tabular}{lcccc}
\hline \multicolumn{1}{c}{ Fruta } & $\begin{array}{c}\text { Acidez (g Ac. } \\
\text { cítrico/100 g muestra) }\end{array}$ & \% celulosa & Densidad (g/mL) & \% humedad \\
\hline Limón & 0.274 & 7.90 & 0.505 & 69.62 \\
Lulo & 0.233 & 8.48 & 0.534 & 79.70 \\
Mango & 0.213 & 17.85 & 1.045 & 77.58 \\
Maracuyá & 0.288 & 7.75 & 0.619 & 79.46 \\
Mora & 0.194 & 16.43 & 0.858 & 70.48 \\
Piña & 0.155 & 2.68 & 1.112 & 81.43 \\
\hline
\end{tabular}

Acidez titulable por volumetría. La tabla 1 muestra los resultados de acidez de cada uno de los residuos previamente seleccionados, expresada en gramos de ácido cítrico (por ser el ácido predominante en las frutas) por cada $100 \mathrm{~g}$ de muestra. Los valores son bajos en comparación con los del propio fruto, debido a que la mayor cantidad de fluidos de las frutas ha sido removida en los procesos primarios de la empresa y el residuo sólido no tiene la misma capacidad de retener el ácido, capacidad que sí tiene el zumo de cada fruto.

Por ejemplo, para el caso de la piña, la cantidad de muestra promedio que se analizó fue 1.033 g y el volumen de solución titulante $0.00025 \mathrm{~L}$, entonces:

$$
\begin{gathered}
\% \text { acidez }=\frac{V_{T} * N * 39.997 * 1.601}{M} * 100 \\
\% \text { acidez }=\frac{0.00025_{T} * 0.1 * 39.997 * 1.601}{1.033} * 100 \\
=0.155 \%\left(\frac{g \text { Ac. Citrico }}{100 g \text { Muestra }}\right)
\end{gathered}
$$

Determinación de celulosa. En la tabla 1 se presentan los porcentajes de celulosa en gramos por cada $100 \mathrm{~g}$ de desecho húmedo del respectivo fruto. La piña es la fruta de menor disponibilidad del polisacárido y el mango es la de mayor contenido; esta variable es importante, ya que teóricamente indica la cantidad máxima de glucosa disponible para la fermentación.

Para conocer la cantidad de celulosa presente en la muestra se desarrolla la siguiente ecuación:

$$
\% \text { celulosa }=\frac{\text { Material } A-\text { Material } B}{\text { Peso de la muestra }} * 100
$$

Donde "material A" y "material B" representan el peso de la muestra después de ser secada e incinerada, respectivamente. Por ejemplo, para la determinación de celulosa del mango, el peso real de la muestra en la primera repetición fue de $0.3271 \mathrm{~g}$; después del secado, $0.0631 \mathrm{~g}$, y posterior a la incineración, $0.0021 \mathrm{~g}$ : 


$$
\% \text { celulosa }=\frac{0.0631-0.0021}{0.3271} * 100=18.65 \%
$$

Para la segunda repetición, el peso de la muestra fue $0.2522 \mathrm{~g}$; después del secado, $0.0442 \mathrm{~g}, \mathrm{y}$ después de la incineración, $0.0012 \mathrm{~g}$; por lo tanto, el porcentaje de celulosa fue $17.05 \%$ y el porcentaje promedio fue $17.85 \%$.

Determinación de densidad. La densidad para el caso del limón se calcula teniendo la masa del residuo $(1.514 \mathrm{~g})$, el volumen inicial de agua $(92 \mathrm{~mL})$ y el volumen final con la muestra $(95 \mathrm{~mL})$.

$$
\rho=\frac{1.514 g}{95 m L-92 m L}=0.505 g / m L
$$

En la tabla 1 se observa que los residuos de mango tienen el mayor porcentaje de celulosa (por su alto contenido fibroso); en consecuencia, esta fruta tiene una mayor densidad.

Determinación de humedad. En la tabla 1 se registran los porcentajes de humedad y se evidencia que todos los resultados están por encima del $69 \%$. El bagazo de piña presenta el mayor contenido de humedad, $81.427 \%$. En términos generales, la humedad podría considerarse como desventaja, debido a que los residuos deben llevarse a un proceso de molienda.

Para el caso del lulo, el peso de la primera y segunda muestra fue $2.0878 \mathrm{~g}$ y $2.0093 \mathrm{~g}$, respectivamente; después del secado el peso fue $0.4511 \mathrm{~g}$ y $0.3816 \mathrm{~g}$, por lo tanto:

$$
\% \text { humedad }=\frac{(2.0878 g-0.4511)}{(2.0878 g)} * 100=78.39 \%
$$

El resultado de la segunda repetición fue $81.01 \%$ y la humedad promedio fue $79.70 \%$.

\section{Determinación de las diferentes combinaciones de los residuos de fruta}

A partir de los porcentajes promedio de celulosa obtenidos en la caracterización de los residuos (ver tabla 2) se establecieron las mezclas pertinentes para el desarrollo de la hidrólisis enzimática y se pesaron $2 \mathrm{~kg}$ de cada una de las mezclas.

Teniendo en cuenta los porcentajes similares de celulosa de cada uno de los residuos y separándolos en tres grupos, bajo, medio y alto porcentaje, se obtuvo que la piña pertenece al primer grupo; el maracuyá, el limón y el lulo, al segundo, y la mora y el mango, al tercero. De este modo, se mezclan entre sí y en proporciones iguales cada una de los residuos en sus respectivos grupos. Se descartó la hidrólisis de la piña por su bajo contenido de celulosa.

Se aclara que se usaron mezclas binarias y en iguales proporciones. Los resultados de este trabajo proporcionarán datos relevantes para investigaciones posteriores que tengan como objetivo desarrollar hidrólisis con más de dos componentes simultáneamente y/o en complejos binarios con fracciones distintas a $50 \%$.

\section{Pretratamiento de los residuos orgánicos}

Se realizó el pretratamiento con $\mathrm{NaOH}$ y en todas las pruebas se perdió el aroma característico de cada fruta; también se evidenciaron ligeras saponificaciones en la superficie del tanque de 
pretratamiento, exceptuando la muestra de limón, la cual solamente perdió su aroma. Al final de los cuatro lavados y respectivos filtrados, las muestras recuperaron ligeramente su aroma.

\section{Hidrólisis enzimática}

En esta etapa, la cantidad de agua que se utilizó por hidrólisis fue de la siguiente: maracuyá-limón: 6 L; maracuyá-lulo: 6 L; limón-lulo: 6 L; mora-mango: 4 L; maracuyá: 6 L; limón: 4 L; lulo: 4 L; mora: $4 \mathrm{~L}$; mango: $6 \mathrm{~L}$.

Se consideró que todas las muestras debían quedar completamente sumergidas para tener mayor movilidad y contacto con la enzima, por lo que los residuos o mezclas quedaron sumergidos en 4 o $6 \mathrm{~L}$ de agua.

\section{Determinación de azúcares por el método DNS}

Aunque los porcentajes de celulosa hacían suponer cuáles serían los residuos con mayores posibilidades para la producción de azúcares, los resultados se comportaron de manera diferente a lo esperado: el mango, con el mayor contenido de celulosa (17.85\%), fue el de menor capacidad para producir azúcares (1.39 g glucosa/L); el limón de las hidrólisis individuales tuvo el mejor rendimiento (1.87 g de glucosa/L), aunque su porcentaje de celulosa era intermedio (7.9\%). Respecto a las mezclas, la combinación mora-mango no fue la mejor, a pesar de tener mayor disponibilidad de polisacárido $(17.14 \%, 1.74 \mathrm{~g}$ glucosa/L); se destacó la mezcla lulo-limón, que superó considerablemente a todas las mezclas y desechos individuales ( $2.08 \mathrm{~g}$ de glucosa/L). La principal variable que afecta este proceso de hidrólisis es el tiempo, debido a que en varios procesos se plantean tiempos de más de $48 \mathrm{~h}$ para hidrólisis enzimática, dependiendo del complejo enzimático y sus condiciones de operación.

También es importante tener en cuenta que los mayores grados de conversión se obtuvieron en los residuos con mayor acidez titulable, lo que puede sugerir que las condiciones ácidas inherentes a cada residuo benefician la hidrólisis y contrarrestan cualquier efecto residual que pudiera llegar a tener el tratamiento con $\mathrm{NaOH}$.

Las concentraciones de azúcares reductores no fueron favorables en comparación con las registradas por otros autores; por ejemplo, Giraldo, Correa, Gutiérrez y Castaño (2007) evidencian un rendimiento superior de azúcares reductores con las enzimas Pectinex $(0.37743 \mathrm{mg}$ de azúcares por cada mg de materia seca) y Celluclast (0.28853 mg de azúcares por cada mg de materia seca) para el residuo del mango; por su parte, Ávila (2015) realizó un proceso de hidrólisis ácida al residuo del maracuyá y obtuvo concentraciones de azúcares entre 3 g/L y 8 g/L. En la tabla 2 se muestran los resultados de los azúcares obtenidos en la hidrólisis.

Tabla 2. Conversión de la enzima Multifect $B$ durante el proceso de hidrólisis

\begin{tabular}{|c|c|}
\hline Muestra & Azúcares obtenidos (g) \\
\hline Maracuyá-limón & 7.54 \\
\hline Maracuyá-lulo & 8.03 \\
\hline Limón-lulo & 10.67 \\
\hline Mora-mango & 6.31 \\
\hline Maracuyá & 9.23 \\
\hline Limón & 7.27 \\
\hline Lulo & 5.45 \\
\hline Mora & 6.92 \\
\hline Mango & 7.85 \\
\hline
\end{tabular}


El rendimiento de la mezcla maracuyá-limón se determinó con base en la cantidad de celulosa:

$C(\%)=7.75 \% * 0.5+7.9 \% * 05=7.83 \%$

Celulosa disponible $(\mathrm{g})=7.83 \% * 2000 \mathrm{~g}=156.5 \mathrm{~g}$ celulosa

$$
\text { Rendimiento }(\%)=\frac{754 g}{156.5 g} * 100=4.82 \%
$$

Los resultados de rendimiento de azúcares para las mezclas y residuos de una sola fruta se muestran en la tabla 3 .

Tabla 3. Rendimiento con base en la cantidad de celulosa

\begin{tabular}{lccc}
\hline \multicolumn{1}{c}{ Muestra } & $\mathbf{C}(\%)$ & Celulosa disponible (g) & Rendimiento (\%) \\
\hline Maracuyá-limón & 7.83 & 156.5 & 4.82 \\
Maracuyá-lulo & 8.12 & 162.3 & 4.95 \\
Limón-lulo & 8.19 & 163.8 & 6.51 \\
Mora-mango & 17.14 & 342.8 & 1.84 \\
Maracuyá & 7.75 & 155.0 & 5.95 \\
Limón & 7.90 & 158.1 & 4.60 \\
Lulo & 8.48 & 169.5 & 3.21 \\
Mora & 16.43 & 328.5 & 2.11 \\
Mango & 17.85 & 357.0 & 2.20 \\
\hline
\end{tabular}

\section{Fermentación}

Se realizaron las cinéticas de crecimiento para cada una de las 9 fermentaciones y se observó que el tiempo en el que se detiene el crecimiento microbiano varía entre 72 h y 108 h. Para determinar la concentración del inóculo se realizaron recuentos en cámara Neubauer hasta alcanzar una concentración entre $1 \times 10^{7}$ y $1 \times 10^{8}$ células $/ \mathrm{mL}$.

La cantidad de células fueron contadas en cámara de Neubauer para cada fermentación (desde el tiempo cero de crecimiento hasta el momento en que este se detiene) y en intervalos de $12 \mathrm{~h}$.

En comparación con otros autores, Adarme y Rincones (2008) presentan un crecimiento logarítmico en las primeras $8 \mathrm{~h}$ de fermentación; los tiempos de crecimiento que se dan en este trabajo son relativamente altos, considerando que las concentraciones de sustrato son menores. Sánchez (2011) muestra una cinética de crecimiento, la cual tiene una fase exponencial entre 5 y 10 días; sin embargo, las concentraciones de azúcares reductores son del orden de $70 \mathrm{~g} / \mathrm{L}$.

Para la determinación del bioetanol obtenido se empleó el método del dicromato de potasio y se calculó el rendimiento del mismo, como se muestra en la tabla 4.

$$
R_{B}=\frac{5.12 \mathrm{~L} * 3.6 \mathrm{~g} / \mathrm{L}}{2 \mathrm{~kg}}=9,22 \frac{\mathrm{g} \text { etanol }}{\mathrm{kg} \text { sustrato }}
$$


Tabla 4. Rendimiento de bioetanol por cada kg de sustrato

\begin{tabular}{lccc}
\hline \multicolumn{1}{c}{ Muestra } & $\begin{array}{c}\text { Volumen final hidrolizado } \\
\mathbf{( L )}\end{array}$ & $\begin{array}{c}\text { Concentración etanol } \\
(\mathbf{g} / \mathbf{L})\end{array}$ & $\begin{array}{c}\text { Rendimiento de bioetanol } \\
(\mathbf{g} / \mathbf{k g})\end{array}$ \\
\hline Limón-lulo & 5.12 & 3.60 & 9.22 \\
Limón & 3.89 & 3.27 & 6.36 \\
Maracuyá & 5.14 & 3.08 & 7.92 \\
Mora & 3.84 & 3.12 & 5.99 \\
Mora-mango & 3.63 & 2.98 & 5.41 \\
Maracuyá-lulo & 5.34 & 2.60 & 6.94 \\
Lulo & 3.79 & 2.54 & 4.81 \\
Maracuyá-limón & 5.35 & 2.49 & 6.66 \\
Mango & 5.64 & 2.43 & 6.85 \\
\hline
\end{tabular}

Los resultados de rendimiento obtenidos, a pesar de no ser viables para producir bioetanol en comparación con los que se obtienen con sustratos ricos en azúcares, como el bagazo de caña de azúcar (0.34 L etano1/kg de bagazo [Forero, 2009]), son altos al ser comparados con los registrados por Tejeda et ál. (2010), en los que de cada kilogramo de cáscara de naranja se produjeron $8.4 \mathrm{~g}$ de etanol y por cada kilogramo de cáscara de piña se obtuvo $1 \mathrm{~g}$ de etanol.

\section{Rendimiento de la fermentación}

Como se presenta en la tabla 5, el rendimiento microbiológico obtenido $\left(\mathrm{Y}_{\mathrm{P} / \mathrm{S}}\right)$ muestra que, en general, la levadura tuvo un rendimiento constante en todas las pruebas realizadas, lo que significa que los medios de cultivo mantuvieron condiciones similares e inocuas que permitieron el crecimiento de la cepa. El rendimiento teórico para la fermentación de glucosa en bioetanol es de $0.511 \mathrm{~g}$ bioetanol $/ \mathrm{g}$ glucosa (Vázquez y Dacosta, 2007). La razón probable por la que en esta experimentación se superó este límite fue que el hidrolizado tenía un contenido de sacarosa que no puede ser leído por el método DNS y que algunas levaduras tenían la enzima invertasa, lo que convierte la sacarosa en glucosa y fructosa.

Tabla 5. Rendimiento $\left(Y_{P / S}\right)$

\begin{tabular}{|c|c|c|c|c|}
\hline Muestra & $\begin{array}{c}\text { Concentración (g } \\
\text { glucosa/L) }\end{array}$ & $\begin{array}{c}\text { Concentración de } \\
\text { alcohol en los } 250 \\
\mathrm{~mL}(\mathrm{~g} / \mathrm{L})\end{array}$ & $\begin{array}{l}\text { Rendimiento de } \\
\text { bioetanol }(\mathrm{g} / \mathrm{kg})\end{array}$ & $\begin{array}{c}\text { Rendimiento }\left(Y_{P / S}\right) \\
\text { (g bioetanol } / \mathbf{g} \\
\text { glucosa) }\end{array}$ \\
\hline Limón-lulo & 2.08 & 3.60 & 9.22 & 0.86 \\
\hline Limón & 1.87 & 3.27 & 6.36 & 0.87 \\
\hline Maracuyá & 1.80 & 3.08 & 7.92 & 0.86 \\
\hline Mora & 1.80 & 3.12 & 5.99 & 0.87 \\
\hline Mora-mango & 1.74 & 2.98 & 5.41 & 0.86 \\
\hline Maracuyá-lulo & 1.50 & 2.60 & 6.94 & 0.86 \\
\hline Lulo & 1.44 & 2.54 & 4.81 & 0.88 \\
\hline Maracuyá-limón & 1.41 & 2.49 & 6.66 & 0.88 \\
\hline Mango & 1.39 & 2.43 & 6.85 & 0.87 \\
\hline
\end{tabular}

Como se puede observar en la figura 1 , el mejor rendimiento en la producción de bioetanol con respecto al volumen de sustrato empleado se presentó en la mezcla limón-lulo. De igual forma, 
el maracuyá, que es uno de los residuos de mayor disponibilidad a lo largo del año, también es conveniente para una posible implementación del proceso de producción de bioetanol en la empresa.

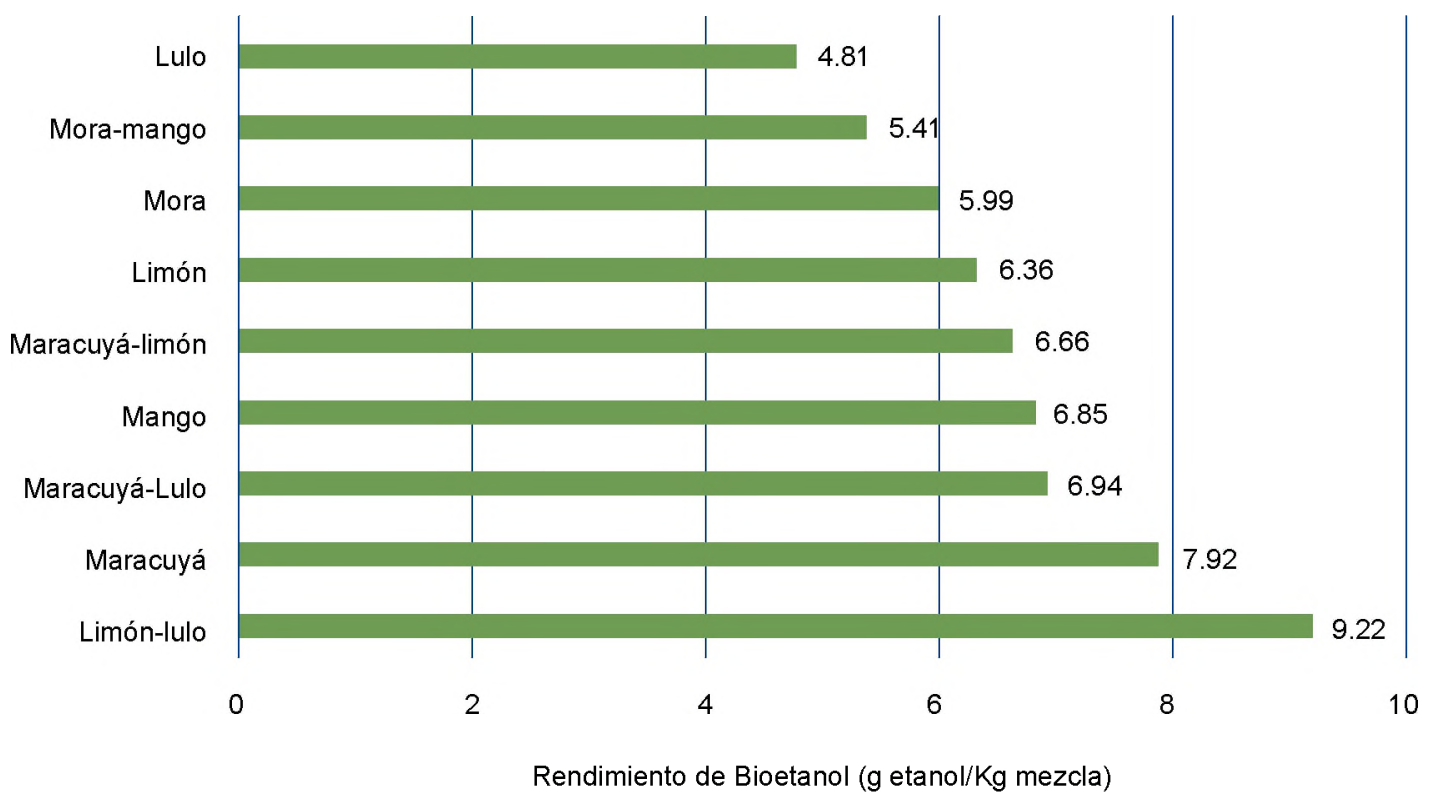

Figura 1. Rendimiento por mezcla y frutas.

Comparando estos resultados con los obtenidos por Buitrago y Tenjo (2007), la levadura tuvo un rendimiento alto de producto; esto debido a que la fuente de carbono es un factor limitante a concentraciones bajas de glucosa, por lo que se obtiene más biomasa y un equilibrio en el número de células, el peso seco, el nitrógeno celular, el RNA y el DNA al producirse a la misma velocidad. En general, la levadura tuvo un rendimiento constante en todas las pruebas realizadas, lo que significa que los medios de cultivo mantuvieron condiciones similares e inocuas que permitieron el crecimiento de la cepa.

\section{Comentarios}

De acuerdo al contenido de celulosa los residuos de limón, maracuyá y lulo, se plantearon mezclas de estas frutas con un porcentaje medio de celulosa en un rango de 7-9\%. De igual forma, el mango y la mora fueron mezclados por ser las muestras con mayor contenido de celulosa, 17.85 y 16.43, respectivamente, esto con el fin de favorecer el proceso de hidrólisis y la posterior fermentación.

El rendimiento obtenido por la mezcla limón-lulo (9.22 g de etanol por kg de limón-lulo) fue mayor al reportado por Tejeda et ál. (2010) para residuos no mezclados ( $8.4 \mathrm{~g}$ de etanol por $\mathrm{kg}$ de cáscara de naranja), lo que permitió comprobar la conveniencia de realizar mezclas de acuerdo con el contenido de azúcares de los residuos.

Los residuos de mayor concentración de celulosa fueron el mango y la mora, con $17.85 \%$ y $16.43 \%$, respectivamente; la densidad también fue mayor en estos dos casos. La humedad estuvo entre 69 y 81 \%, razón por la cual, en comparación con la mezcla lulo-limón, el rendimiento fue menor, incluso considerando la mayor concentración de celulosa. Se establece que el contenido de humedad es un factor relevante en el rendimiento de la producción de bioetanol, puntualmente, en la etapa de hidrólisis. La mezcla con mayor concentración de azúcares reductores fue lulo-limón, con 
un $2.08 \mathrm{~g}$ glucosa $/ \mathrm{L}$ y $9.22 \mathrm{~g}$ bioetanol $/ \mathrm{kg}$, que resulta aceptable comparada con lo registrado por Tejeda et ál. (2010), puesto que en este estudio se determinó que por cada kilogramo de cáscara de piña se obtiene $1.0 \mathrm{~g}$ de bioetanol.

El rendimiento de la producción de bioetanol fue mayor al esperado, con un valor de $0.87 \mathrm{~g}$ bioetanol/g glucosa en promedio, comparado con el rendimiento teórico para la fermentación de glucosa en bioetanol de $0.511 \mathrm{~g}$ bioetanol/g de glucosa (Vázquez y Dacosta, 2007), debido probablemente a que el hidrolizado contenía sacarosa y que algunas levaduras tenían la enzima invertasa, que tiene la capacidad de convertir la sacarosa en glucosa y fructosa, las cuales al fermentarse aumentan el rendimiento del bioetanol con relación a la cantidad de residuo empleado.

Los resultados obtenidos son convenientes para la empresa de alimentos, que a mediano plazo puede llevar a cabo la evaluación de la producción de bioetanol a partir de las mezclas propuestas y de esta forma constituir una nueva línea de negocio, valorizar los residuos generados en sus procesos y fortalecer un modelo de producción sostenible.

\section{REFERENCIAS}

Adarme T., y Rincones, M. (2008). Evaluación de cuatro antimicrobianos para el control de levaduras contaminantes de un proceso de fermentación de ácido cítrico (tesis de pregrado). Facultad de Ciencias, Pontificia Universidad Javeriana, Bogotá, Colombia.

Amarís, J., Manrique, D., y Jaramillo, J. (2015). Biocombustibles líquidos en colombia y su impacto en motores de combustión interna. Una revisión. Revista Fuentes. El Reventón Energético, 13(2), 23-34. doi:10.18273/revfue.v13n2-2015003

Ávila, L. (2015). Obtención de bioetanol de segunda generación a partir del pericarpio de maracuyá (Passiflora edulisf. flavicarpa) (tesis de pregrado). Facultad de Ciencias Químicas, Universidad de Cuenca, Cuenca, Ecuador.

Buitrago, J., y Tenjo, D. (2007). Obtención de un sustrato fermentable de origen vegetal y su evaluación con células libres de Saccharomyces cerevisiae. Facultad de Ciencias, Pontificia Universidad Javeriana, Bogotá, Colombia.

Domínguez, E., Cortés, V., Ávila, R., Olvera, L., Vernon, J., Bosquez, E., y Domínguez, J. (2003). Aumento de la vida postcosecha del limón mexicano (citrus aurantifolia swingle) producido en apatzingán, mich., mediante el uso de recubrimientos naturales a diferentes temperaturas de almacenamiento. Revista Iberoamericana de Tecnología Postcosecha, 5(2), 128-133.

Forero, F., López, R., y Malagón, M. (2008). Obtención del etanol a partir de brócoli y cáscara de arveja empleando la enzima multifect 720 de caracter básico a nivel de laboratorio. Ponencia presentada en Simposio de Quimica Aplicada-SIQUIA, Universidad de Quindio, Armenia, Colombia.

Forero, O. (2009). El bagazo de caña de azúcar, petróleo verde del siglo. Dinero. Recuperada de http://www.dinero.com/green/seccion-patrocinios/articulo/el-bagazo-cana-azucar-petroleo-verde-del-siglo/82610

Giraldo, L., Correa, H., Gutiérrez, J., y Castaño, C. (2007). Aprovechamiento del residuo agroindustrial del mango común (Mangifera indica L.) en la obtención de azúcares fermentables. Ingenieria y Ciencia, 3(6), 41-62. 
Márquez, C. (2009). Caracterización fisiológica, físicoquímica, reológica, nutracéutica, estructural y sensorial de la guanábana (Annona muricata L. cv. elita) (tesis doctoral).Doctorado en Ciencia, Universidad Nacional de Colombia, Medellín, Colombia.

Martínez, A., del Ángel, A., Martínez, L., Román, A., y Uriza, D. (2006). Rendimiento y calidad de fruto de cultivares de piña en densidades de plantación. Revista Fitotecnia Mexicana, 29(1), 55-62.

Miller, G. L. (1959). Use of dinitrosalicylic acid reagent tor determination of reducing sugar. Analytical Chemistry, 31(3), 426-428.

Ministerio de Ambiente y Desarrollo Sostenible. (2015). Colombia se compromete a reducir el 20\% de sus emisiones de gases de efecto invernadero para el año 2030. Recuperado de https:/www.minambiente.gov.co/index.php/component/content/article/2-noticias/1913colombia-se-compromete-a-reducir-el-20-de-sus-emisiones-de-gases-de-efecto-invernadero-para-el-ano-2030

Montoya, A., Londoño, J., y Márquez, C. (2005). Licor de mora de castilla (Rubus glaucus Benth) con diferentes porcentajes de pulpa. Revista Facultad Nacional de Agronomia, 58(2), 29632974.

Rodríguez, L., López, L., y García, M. (2010). Determinación de la composición química y actividad antioxidante en distintos estados de madurez de frutas de consumo habitual en Colombia, mora (Rubus glaucus b.), maracuyá (Passiflora edulis s.), guayaba (Psidium guajava l.) y papayuela (Carica cundinam). Alimentos Hoy, 19(21), 35-42.

Sanchez, A. (2011). Fermentación de malta empleando un sistema semicontinuo en el proceso de elaboración de cerveza (tesis de pregrado).Universidad Tecnológica de la Mixteca, Oaxaca, México.

Segura, F., Echeverry, R., Patiño, A., y Mejía, A. (2007). Descripción y discusión acerca de los métodos de análisis de fibra y del valor nutricional de forrajes y alimentos para animales. Revista de la Facultad de Quimica Farmacéutica, 14(1), 72-81.

Serna, F., Barrera, L., y Montiel, H. (2011). Impacto social y económico en el uso de biocombustibles. Journal of Technology Management E Innovation, 6(1), 100-114.

Siller, J., Muy, D., Báez, M., Araiza, E., y Araiza, E. (2009). Calidad poscosecha de cultivares de mango de maduración temprana, intermedia y tardía. Revista Fitotecnia Mexicana, 32(1), 45-52.

Tejeda, L., Tejada, C., Villabona, A., Alvear, M., Castillo, C., Henao, D., Marimón, W., Madariaga, N., y Tarón, A. (2010). Producción de bioetanol a partir de la fermentación alcohólica de jarabes glucosados derivados de cáscaras de naranja y piña. Revista Educación en Ingeniería, $5(10), 120-125$.

Vanegas, M., y Zapata, M. (2009). Aislamiento de levaduras capaces de producir alcohol a partir de macrofitas acuáticas extraidas mecánicamente de la laguna de fúquene (tesis de pregrado). Facultad de Ciencias, Pontificia Universidad Javeriana, Bogotá, Colombia.

Vázquez, H., y Dacosta, O. (2007). Fermentación alcohólica: una opción para la producción de energía renovable a partir de desechos agrícolas. Ingeniería, Investigación y Tecnología, 8(4), 249-259. 
